\title{
UMA EXPERIÊNCIA DE EDUCAÇÃO NUTRICIONAL NO ENQUADRE TERAPÊUTICO DA DEPENDÊNCIA QUÍMICA
}

\author{
Luana Baldissera, Camila Tonini, Kerlyn Maharish Zanon \\ Acadêmicas do Curso de Nutrição da UNOCHAPECÓ \\ Dra. Carla Rosane Paz Arruda Teo \\ Professora do Centro de Ciências da Saúde da UNOCHAPECÓ (Coordenadora) \\ carlateo@unochapeco.edu.br
}

\section{Resumo}

A dependência química é um problema de saúde pública para o qual estão direcionadas inúmeras abordagens terapêuticas. Este trabalho apresenta uma experiência de educação nutricional humanizada, com os objetivos de contribuir para a qualidade de vida de dependentes químicos e de oportunizar acadêmicos de nutrição a vivenciarem o perfil profissional proposto pelo projeto pedagógico norteador de sua formação. A experiência foi avaliada positivamente por todos os atores envolvidos.

Palavras-chave: Formação em saúde. Oficinas culinárias. Discurso do sujeito coletivo.

\section{A NUTRITION EDUCATION EXPERIENCE IN THERAPEUTIC SETTING OF CHEMICAL DEPENDENCY}

\begin{abstract}
The addiction is a public health problem for which many therapeutic approaches are directed. This paper presents an experience in humanized nutrition education, aiming to contribute to the quality of life of chemical dependents and to give students a chance for practicing the professional profile proposed by the pedagogical project that guides their educational training. The experience was positively evaluated by all involved.
\end{abstract}

Keywords: Training in health. Culinary workshops. Collective subject speech. 


\section{Introdução}

O consumo de substâncias capazes de alterar estados de consciência e de modificar o comportamento é um fenômeno universal na história da humanidade, havendo em todas as culturas e épocas o relato do uso de substâncias que favorecem o relacionamento social, marcam festividades ou tem papel simbólico em rituais de cunho místico ou religioso (SCHLICTING, BOOG \& CAMPOS, 2007). O uso/abuso dessas substâncias constitui um fenômeno complexo com origens e consequências biológicas, psicológicas e sociais (AGUILAR \& PILLON, 2005) cujo reconhecimento como um problema de saúde é recente (MENDES \& VILLAR, 2004).

Apenas a partir da segunda metade do século XX, o conceito de dependência deixou de ser o de desvio de caráter para assumir contornos de transtorno mental. A partir de então, tem sido crescente a necessidade de organizar serviços que atendam aos usuários em diferentes estágios e desenvolvam ações que promovam efetivamente sua reabilitação e qualidade de vida (RIBEIRO, 2004). Em termos de políticas públicas, surge no Brasil, em 2003, a Política de Atenção Integral aos Usuários de Álcool e Outras Drogas, estabelecida pelo Ministério da Saúde e fundamentada na reabilitação e reinserção social dos dependentes, na lógica da redução de danos ${ }^{1}$ (BRASIL, 2003).

O Centro Terapêutico Dilso Cechin (CETER), fundado em 1995 e onde foi desenvolvido o projeto de extensão Apoio Nutricional, é uma casa de recuperação sem fins lucrativos e de interesse público, mantido através de doações do Lions Clube Integração de Chapecó e da comunidade em geral, que atua na recuperação de homens, maiores de 18 anos, usuários de álcool e de outras drogas com modelo de tratamento integral e duração entre seis e nove meses.

A exemplo das, assim denominadas, comunidades terapêuticas, o CETER trabalha a partir de alguns pressupostos: regime de residência com internação e permanência voluntárias e possibilidade de interrupção do tratamento a qualquer tempo, oferta de ambiente protegido, técnica e eticamente orientado, tendo a laborterapia e a convivência com os pares como instrumentos terapêuticos.

De forma geral, há uma variedade de profissionais que podem estar envolvidos no enquadre terapêutico da dependência química, entendido como o ambiente/tipo de tratamento e a composição da equipe. Embora este enquadre varie substancialmente entre os diferentes

\footnotetext{
${ }^{1}$ A redução de danos é uma abordagem que tem por finalidade prevenir ou amenizar consequências danosas à saúde do usuário de álcool e outras drogas, tais como as doenças sexualmente transmissíveis e a desnutrição, sem necessariamente interferir na oferta ou na demanda (RIBEIRO, 2004).
} 
centros e níveis de tratamento (RIBEIRO, 2004), o profissional nutricionista não costuma ser um integrante da equipe, a despeito do reconhecido comprometimento nutricional do dependente químico (MAIO, DICHI e BURINI, 2000; PAULA et al., 2006; SCHLICTING, BOOG e CAMPOS, 2007).

Neste contexto, foi desenvolvido o projeto Apoio Nutricional, segundo o princípio da redução de danos e com o objetivo principal de contribuir para a melhoria da qualidade de vida dos internos do CETER a partir de ações de educação nutricional. Na perspectiva da indissociabilidade entre ensino, pesquisa e extensão, um segundo objetivo, não menos importante, foi o de oportunizar aos acadêmicos, a partir do contato com a realidade concreta, o exercício do processo de ação - reflexão - ação na construção de referenciais para o cuidado integral em nutrição, contribuindo para a formação de um perfil profissional humanista, em consonância com o projeto político-pedagógico do Curso de Nutrição da Unochapecó (UNOCHAPECÓ, 2005), orientado pelas Diretrizes Curriculares Nacionais para a formação na área da saúde (BRASIL, 2001).

\section{Material e Métodos}

O projeto Apoio Nutricional foi desenvolvido, entre março e dezembro do ano de 2007, por três acadêmicas do Curso de Nutrição da Universidade Comunitária Regional de Chapecó (Unochapecó), sob orientação docente e com financiamento do Fundo de Apoio à Extensão (FAPEX). A estratégia adotada foi a realização de um encontro semanal com os internos do CETER, em um dia fixo da semana, de maneira a não comprometer a rotina de atividades do centro e, ainda, a fim de evidenciar o comprometimento da equipe de nutrição com os internos, a equipe destinava aquela tarde para o grupo, nunca sendo o encontro transferido, desmarcado ou abreviado.

Neste sentido, Freitas (2001) pondera que, ao nos propormos desenvolver ações de atenção em saúde, é fundamental que façamos uma reflexão acerca de nosso comprometimento com os sujeitos que, conosco, compartilham um tempo e um espaço, num esforço pela superação de nossas impossibilidades em direção à expressão de nossas capacidades humanas.

Quanto aos internos, os mesmos constituíam um grupo aberto de livre demanda, isto é, todos os internos poderiam participar, ou não, de quantos encontros desejassem.

Cada encontro foi conduzido, basicamente, em três momentos: integração, educação nutricional, fechamento. A integração era o momento de mobilização dos internos para o 
encontro, de apresentação dos novos internos, de breves relatos informais sobre os acontecimentos da última semana, de forma a canalizar a concentração dos participantes para as atividades previstas para aquele encontro, criando um ambiente harmonioso e favorável.

A educação nutricional foi realizada através de diferentes dinâmicas de grupo descritas na literatura (BERKENBROCK, 2003) e ou adaptadas da mídia televisiva e sempre tendo um tema central. A escolha do tema para a educação nutricional foi feita pela equipe de nutrição em algumas ocasiões, como nos primeiros encontros ou quando percebia que algum tema se adequava melhor às características dos internos. Por exemplo, quando havia muitos internos novos, a equipe elegia um tema que proporcionasse conceitos básicos para a educação nutricional. Em outras ocasiões, os próprios internos sugeriam o tema para discussão no próximo encontro, em função de seus interesses enquanto grupo.

Uma dinâmica frequentemente utilizada foi a da oficina culinária, já que a mesma, além de ser um recurso para a laborterapia (princípio do tratamento), possibilita a abordagem dos hábitos alimentares dos internos e de temas afins. A oficina culinária surge, em educação nutricional, como uma estratégia efetiva de promoção da saúde a partir do desenvolvimento de habilidades pessoais, pelo estímulo à autonomia e atitude protagonista dos participantes (CASTRO et al. 2007).

Neste projeto, a dinâmica consistia em fornecer algumas receitas aos internos, que deveriam se organizar e, coletivamente, elaborar as preparações sob orientação da equipe de nutrição. As receitas trabalhadas nas oficinas culinárias foram selecionadas de forma a melhorar o consumo de nutrientes específicos entre os internos (como, por exemplo, fibras, minerais, proteínas, etc.) e estimular: a) o consumo de alimentos de adequado valor nutricional e de baixa aceitabilidade entre os internos; b) o consumo de alimentos produzidos na horta do CETER; c) o consumo de alimentos de adequado valor nutricional que frequentemente estão disponíveis no CETER em função de doações e d) o aproveitamento integral dos alimentos disponíveis.

O fechamento era um momento de motivação e apoio aos internos, pois contribuía para a construção e consolidação do vínculo afetivo entre a equipe e os internos. O fechamento se fazia com músicas, mensagens de motivação e ou espiritualidade. Esta atitude da equipe, de buscar revestir de afetividade o vínculo profissional que se estabelecia, revela a base teórica que fundamenta este trabalho, assumindo os pressupostos de que toda a aprendizagem só se processa em ambiente relacional positivo porque depende da interação com o outro (WALDOW, 2004; DEMO, 2006) e de que a humanização do cuidado em saúde é a concretização do discurso acerca da visão integral do homem, como ser biopsicossocial. 
A título de avaliação, em dois momentos durante a realização do projeto (junho e dezembro), os internos foram solicitados a responder a seguinte pergunta: quais contribuições a equipe de nutrição ofereceu para a sua permanência no CETER? As respostas fornecidas foram analisadas segundo a metodologia do Discurso do Sujeito Coletivo - DSC ${ }^{2}$, a qual prepara as informações para que revelem o que pensam as coletividades, ou seja, conforma descritivamente a opinião de uma coletividade, no caso, a coletividade dos internos do CETER (LEFEVRE \& LEFEVRE, 2005). A análise foi realizada através do software Qualiquantisoft ${ }^{\circledR}$ (IPDSC, 2007).

Ao término das atividades do projeto, em dezembro, foi solicitada uma avaliação semelhante aos funcionários do CETER, com a seguinte pergunta: como avaliam o trabalho desenvolvido pelas estagiárias de nutrição no CETER? A análise das respostas foi também realizada pela metodologia do DSC.

\section{Resultados e Análise}

Foram realizados 33 encontros durante o desenvolvimento do projeto, sendo de 88 o número total de internos do CETER no período. A adesão ao projeto foi de 100,0\%, com todos os internos participando de cada encontro promovido pela equipe de nutrição.

Com relação aos temas para a educação nutricional, em 19 (57,8\%) dos encontros foi abordado o tema Alimentação Saudável, em cinco (15,2\%) o tema foi Alimentos Funcionais, em três (9,0\%) foi Efeitos das Drogas de Dependência e Interação Fármacos/Nutrientes, em dois (6,0\%) o tema foi Higiene (Pessoal, de Alimentos e de Ambiente) e em outros dois (6,0\%) foi Alimentação e Atividade Física, em um (3,0\%) encontro o tema foi Alimentos Diet e Light e em um (3,0\%) foi Mitos Alimentares.

Foram realizadas 15 oficinas culinárias, ao término das quais todos degustavam as preparações elaboradas. Foram produzidas sete receitas de bebidas à base de iogurte e sucos (de hortaliças, frutas e ou cascas), sete receitas salgadas à base de hortaliças, farinhas integrais, soja, talos e cascas de hortaliças e frutas, nove receitas doces à base de hortaliças, soja e feijão, talos e cascas de hortaliças e frutas. Nestas ocasiões, os internos participavam ativamente, solicitando cópias das receitas e fazendo comentários que evidenciavam sua satisfação com as atividades, como: acho bem legal isso, porque estou aprendendo; no próximo encontro quero ajudar a fazer novamente; vou copiar a receita para fazer para a

\footnotetext{
${ }^{2}$ O DSC é uma forma de representar o pensamento de uma coletividade, o que é feito através de uma série de operações sobre os depoimentos, que culmina em discursos-síntese que reúnem respostas de diferentes sujeitos, com conteúdos discursivos de sentido semelhante (LEFEVRE \& LEFEVRE, 2006).
} 
minha mulher quando sair daqui; nossa, estou aprendendo! Nunca havia feito e nem tinha ideia!

Estas falas dos internos evidenciam os benefícios da laborterapia, pela sua mobilização em torno das atividades, pelo sentimento de provisoriedade do tratamento que se expressa na perspectiva de sair e levar para o seu grupo familiar experiências vividas nesta etapa, pela melhoria da autoestima que pode ser construída quando o interno se percebe aprendendo algo que é novo e que não lhe ocorreria aprender antes.

Além disso, as oficinas culinárias permitem a valorização das dimensões social e cultural da alimentação, tendo instigado os internos a reflexões sobre o comer, incluindo suas concepções sobre os alimentos e sobre o preparo dos mesmos. Conforme já mencionado por Castro e colaboradores (2007), esta dinâmica possibilita a superação das abordagens tradicionais empregadas em educação nutricional, focadas no valor nutricional e na qualidade higiênica dos alimentos.

A adesão às oficinas culinárias e a satisfação com as mesmas eram evidentes e, respondendo às solicitações dos internos, no último encontro, em dezembro, cada um recebeu um Caderno de Receitas, com as fichas técnicas de todas as preparações por eles elaboradas. Estas fichas técnicas, além dos ingredientes e modo de preparo de cada preparação, continham sua composição nutricional total e na porção recomendada para consumo, bem como a indicação de seus benefícios.

Todas as demais atividades de educação nutricional tinham uma avaliação ao final, como, por exemplo, a seguinte: após uma dinâmica de grupo sobre a Pirâmide dos Alimentos, cada interno recebeu um prato de papel para desenhar como seria a montagem de uma refeição saudável. Nesta ocasião, observou-se que todos tinham entendimento do tema. Em outra ocasião, os internos construíram uma Pirâmide dos Alimentos com papel pardo e figuras de revistas, demonstrando apreensão dos conceitos básicos. Em outras situações, realizava-se a avaliação com a dinâmica Passa ou Repassa, por exemplo, segundo a qual os internos, divididos em dois grupos, respondiam (e marcavam ponto) ou repassavam (e davam a oportunidade do outro grupo marcar ponto) perguntas sobre o tema trabalhado.

Com o tema Higiene, além dos resultados positivos observados nas avaliações mencionadas, a exemplo do que ocorreu com os demais temas, ainda podem ser mencionadas a instalação de telas para evitar a entrada de insetos na cozinha e o fato dos internos terem incorporado procedimentos de desinfecção de alimentos vegetais, utensílios e bancadas durante a preparação de refeições no CETER, tarefa que lhes é atribuída como atividade de laborterapia. 
Apesar dos resultados percebidos pela equipe terem sido avaliados invariavelmente como positivos, era necessário dar concretude a esta avaliação, o que foi feito pela análise das falas dos internos a respeito das contribuições da equipe de nutrição à sua permanência no CETER. Os resultados desta análise foram expressos em termos das ideias centrais (IC) contidas nas falas dos internos.

\section{IC - Aprendizagem}

Aprendi muitas coisas que não sabia e que vão ser muito úteis para mim. Espero que vocês também tenham aprendido algo comigo para suas vidas e que vocês permaneçam aqui para eu aprender mais coisas.

Este discurso, mais do que expressar a percepção do coletivo de internos de que houve aprendizagem e de que a mesma foi uma contribuição no enquadre terapêutico, apresenta o conceito de aprendizagem na interação com o outro, de aprendizagem mútua, de troca. Essa concepção está afinada com os pressupostos teóricos da formação profissional em saúde, que apontam para um perfil humanista, comprometido com a realidade, capaz de um olhar integral ao homem e preparados para a educação permanente, o que implica habilidade e atitude para a aprendizagem contínua, autônoma e independente, mas na interação com os pares e com os sujeitos de sua prática (WALDOW, 2004).

Demo (2006) afirma, inclusive, que aprender não é uma coisa que acontece por transferência de conteúdos e conceitos. Aprender, segundo o autor, passa pela interpretação e reconstrução do saber pelo sujeito e quando isso acontece no grupo pode vir a ser uma das aprendizagens mais promissoras.

\section{IC - Afetividade}

Vocês trouxeram muitas lições de vida e motivação através de suas atitudes, suas palavras. Todas as semanas se dedicam a nós, são atenciosas, responsáveis e excelentes profissionais. São muito queridas e dão uma super explicação, eu consigo entender perfeitamente, eu adoro! Os encontros trouxeram distração, motivação, foram dias divertidos, dinâmicos. Passei os melhores tempos da minha vida! A cada dia que passa confio mais no trabalho da nutrição. Que Deus as conserve, sempre assim, seres humanos especiais, porque é com pessoas como vocês que busco forças para viver lúcido. Muito obrigado pelas aulas, pela atenção e por esses dias. Com carinho. Um grande abraço.

Neste discurso ficam claras a afetividade e a confiança. A construção de vínculos de afetividade e, consequentemente, de confiança eram esperadas, para a criação de um ambiente relacional propício para o desenvolvimento do trabalho de forma a melhorar a qualidade de vida dos internos a partir de um fazer profissional humanizado. Uma relação importante 
implícita nesta fala é a da afetividade como facilitadora da aprendizagem, o que encontra respaldo em Freitas (2001), quando a autora propõe que o fazer humanizado em saúde só será efetivo quando mobilizarmos nossa sensibilidade e afetividade de forma articulada aos saberes técnico-científicos que dominamos.

Este fazer humanizado tem como um de seus pressupostos a aceitação e o respeito ao outro como ele é e não como se idealiza que deveria ser (WALDOW, 2004), para, a partir da construção de vínculos de afetividade e de confiança, estabelecer possibilidades emancipadoras (FREITAS, 2001). Como um indicativo de que, a despeito do avanço da discussão nesta área, estes pressupostos não norteiam a prática ainda hoje hegemônica em atenção à saúde, surge também no discurso dos internos a gratidão, provavelmente decorrente da marginalização social da qual o dependente é alvo, a qual é manifesta inclusive pelas ações prescritivas de profissionais da saúde.

\section{IC - Educação nutricional}

É essencial para aqueles que, como eu, estão em recuperação e debilitados pelo uso de drogas. Eu acho isso muito importante, pois está me ajudando no tratamento, no sentido de trazer informações e orientações nutricionais. Através de vocês eu sei como cuidar da minha alimentação. Procuro observar todas as dicas de tratamento, pois preciso muito. Achei um dos melhores trabalhos da casa.

Aqui está demonstrada que, apesar da ênfase colocada na afetividade, a apreensão e a utilização dos conceitos específicos em nutrição aconteceram e que os mesmos são valorados pelos internos, o que indica que a afetividade apenas contribui para o processo de aprendizagem, não sendo a principal geradora, ou pelo menos não a única, da avaliação positiva do trabalho. Ou seja, a superação da abordagem tradicional prescritiva em educação nutricional não implica relegar o saber técnico-científico na área a um segundo plano, mas apenas estabelecer uma relação horizontal para o cuidado em nutrição.

\section{IC - Outras aprendizagens}

Eu não sabia fazer bolo e nunca tinha comido bolo feito de casca de abóbora! Achava que essas coisas eram só prá mulheres. Mas não aprendi só sobre alimentos. Também aprendi que sou capaz de me recuperar e voltar ao convívio social. Os encontros foram de extrema importância para mim, pois me ajudaram a repensar a maneira como estava me alimentando e até como estava vivendo. Pude perceber que a pessoa humana também é resultado daquilo que se alimenta, então hoje sou uma pessoa melhor.

Este discurso corrobora a efetividade da abordagem humanizada para o sucesso da terapêutica, de forma que outras aprendizagens para além das técnico-científicas foram 
possíveis, como a quebra de paradigmas de gênero, a construção de novos olhares sobre os alimentos (quando da surpresa pelo uso de cascas), o autoconhecimento e a revisão de conceitos. No dizer de Freitas (2001), uma relação emancipadora foi estabelecida.

Interessante também a associação, presente no discurso, entre a alimentação e a forma de viver, pela ideia de que o homem é resultado do que come, assim como é resultado da opção pela dependência ou pelo enfrentamento dela. A própria autoestima aparece incrementada na fala, quando o sujeito autoavalia-se como uma pessoa melhor pelo enfrentamento da dependência e capaz de se recuperar.

Ainda na lógica de dar concretude às percepções da equipe sobre os resultados alcançados com suas ações, agora na perspectiva do serviço, as falas dos funcionários do CETER sobre o trabalho desenvolvido foram submetidas à análise de DSC, resultando no discurso-síntese apresentado a seguir:

\section{IC - Relevância/impacto do trabalho}

Para mim, o trabalho da nutrição é de muita importância e espero que ele continue nos próximos semestres, pois veio a colaborar com o CETER, principalmente no uso de alimentos e pelas orientações que repassam aos internos. É muito diferente para os internos receberem orientações de profissionais: eles escutam e acatam as orientações. Agora, consigo utilizar alimentos que antes eram perdidos.

Este discurso reitera comentários que já haviam sido verbalizados diversas vezes ao longo do desenvolvimento do projeto, quando os funcionários do CETER relatavam a satisfação de observar que alimentos de baixíssima aceitação, como a proteína de soja, que era o exemplo mais claro, começavam a ser bem aceitos, evitando desperdícios. Além disso, comentava-se também sobre a melhoria do autocuidado dos internos.

\section{Considerações Finais}

Os objetivos colocados pelo projeto Apoio Nutricional foram plenamente atingidos, conforme evidenciado pela avaliação dos atores envolvidos nas atividades. A melhoria da qualidade de vida dos internos a partir da potencialização do enquadre terapêutico foi destacada tanto pelos internos quanto pelos representantes do serviço.

Da mesma forma, a inserção na realidade concreta possibilitou às acadêmicas a construção de referenciais para o cuidado integral humanizado em nutrição, pressuposto que é dado pelo projeto pedagógico do curso e orientado pelas Diretrizes Curriculares Nacionais, 
mas que ainda não resultou, de uma forma geral, em superação da abordagem tradicional tecnicista e prescritiva em termos de atenção à saúde.

Desta forma, para além dos objetivos do projeto, um ponto positivo a ser destacado é a clareza com que se colocam, após este processo de ação - reflexão - ação, as possibilidades futuras quanto à articulação entre ensino, pesquisa e extensão, particularmente no que diz respeito a temas afins à formação profissional em saúde.

\section{Referências}

AGUILAR, L.R.; PILLON, S.C. Percepción de tentaciones de uso de drogas em personas que reciben tratamiento. Revista Latino-americana de Enfermagem, São Paulo, v.13, número especial, p. 790-797, 2005.

BERKENBROCK, V.J. Dinâmicas para encontros de grupo. Petrópolis, RJ: Vozes, 2003, 152p.

BRASIL. Ministério da Educação e Cultura. Departamento de Política do Ensino Superior. Diretrizes curriculares nacionais para o curso de graduação em nutrição. Brasília: MEC, 2001.

BRASIL. Ministério da Saúde. Secretaria Executiva. Secretaria de Atenção à Saúde. Coordenação Nacional DST/Aids. A política do Ministério da Saúde para a atenção integral a usuários de álcool e outras drogas. Brasília: MS, 2003.

DEMO, Pedro. Aprender em equipe. 2006. Disponível em http://pedrodemo.blog.uol.com.br/. Acesso em 09/03/2007.

CASTRO, I.R.R. et al. A culinária na promoção da alimentação saudável: delineamento e experimentação de método educativo dirigido a adolescentes e a profissionais das redes de saúde e de educação. Revista de Nutrição, Campinas, v.20, n.6, p.571-588, nov/dez, 2007.

FREITAS, K.S.S. O vôo da arte e educação no cuidado do ser. Erechim, RS: EdiFAPES, 2001, 208p.

IPDSC (2007) Instituto de Pesquisa do Discurso do Sujeito Coletivo. Qualiquantisoft. Disponível em < http://www.fsp.usp.br/ flefevre/Discurso_o_software.htm> . Acesso em 10 dez.2007. 
LEFEVRE, L.; LEFEVRE, A.M.C. Depoimentos e Discursos: uma proposta de análise em pesquisa social. Brasília, DF: Líber Livro Editora, 2005, 97p.

LEFEVRE, L.; LEFEVRE, A.M.C. O sujeito coletivo que fala. Interface, São Paulo, v.10, n.20, p.517-524, jul/dez, 2006.

MAIO, R; DICHI, J.B.; BURINI, R.C. Implicações do alcoolismo e da doença hepática crônica sobre o metabolismo de micronutrientes. Arquivos de Gastroenterologia, v.37, n.2, p.120-124, abr/jun, 2000.

MENDES, I.A.C.; VILLAR, L.M.A. Use of psychoactive substances: a new-old challenge. Revista Latino-americana de Enfermagem, São Paulo, v.12, número especial, p. 295-300, 2004.

PAULA, T.P. et al. Aspectos metabólicos da vitamina A e doença hepática alcoólica. Revista de Nutrição, Campinas, v. 19, n.5, p.601-610, set/out, 2006.

RIBEIRO, M. Organização de serviços para o tratamento da dependência do álcool. Revista Brasileira de Psiquiatria, v.26, suplemento, p.59-62, 2004.

SCHLICTING, S.; BOOG, M.C.F.; CAMPOS, C.J.G. Almoço como momento terapêutico: uma abordagem de educação em saúde com mulheres alcoolistas. Revista Latino-americana de Enfermagem, São Paulo, v.15, n.3, p. 384-390, 2007.

UNOCHAPECÓ - Universidade Comunitária Regional de Chapecó. Projeto políticopedagógico do curso de nutrição. Chapecó, SC, 2005.

WALDOW, V.R. O cuidado na saúde: as relações entre o eu, o outro e o cosmos. Petrópolis, RJ: Vozes, 2004, 240p. 